\title{
Unstable B7-H4 cell surface expression and T-cell redirection as a means of cancer therapy
}

\author{
AKIRA IIZUKA $^{1}$, RYOTA KONDOU ${ }^{1}$, CHIZU NONOMURA $^{1}$, TADASHI ASHIZAWA ${ }^{1}$, \\ KEIICHI OHSHIMA ${ }^{2}$, MASATOSHI KUSUHARA ${ }^{3}$, MITSUHIRO ISAKA ${ }^{4}$, \\ YASUHISA OHDE $^{4}, \mathrm{KEN}^{\text {YAMAGUCHI }}{ }^{5}$ and YASUTO AKIYAMA ${ }^{1}$
}

\begin{abstract}
Divisions of ${ }^{1}$ Immunotherapy, ${ }^{2}$ Medical Genetics and ${ }^{3}$ Regional Resources, Shizuoka Cancer Center Research Institute, Shizuoka 411-8777; ${ }^{4}$ Division of Thoracic Surgery and ${ }^{5}$ Office of the President, Shizuoka

Cancer Center Hospital, Nagaizumi-cho, Sunto-gun, Shizuoka 411-8777, Japan
\end{abstract}

Received April 12, 2016; Accepted May 7, 2016

DOI: $10.3892 /$ or.2016.5084

\begin{abstract}
Tumor immune regulation has been demonstrated in clinical studies using antibodies targeted to the B7/CD28 family. B7 homolog 4 (B7-H4) negatively regulates immune responses and is overexpressed in many types of human cancer, indicating that B7-H4 may be a potential target of cancer therapy. B7-H4 expression is affected by the microenvironment, and its presence has been reported in cancer tissues and immune cells. We found an upregulation of B7-H4 expression using comprehensive whole exome sequencing and gene expression profiling (project HOPE) launched by the Shizuoka Cancer Center based on tumor tissue samples from 1,058 cancer patients. We were successful in producing monoclonal antibodies for B7-H4 and demonstrated B7-H4 dimerization and rapid cell surface disappearance by antibody cross-linking in breast cancer cells, even under typical conditions. These observations may explain why antibody-dependent cellular cytotoxicity (ADCC) did not function in vivo on the B7-H4expressing tumor cells. Unstable cell surface antigens are not suitable as targets for ADCC, and we therefore performed an indirect ADCC-redirecting T-cell cytotoxicity assay to study B7-H4 using polyclonal anti-mouse IgG antibody-mediated linking. Our results showed the possibility of targeting the B7-H4 molecule as a means of treating cancer.
\end{abstract}

Correspondence to: Dr Yasuto Akiyama, Division of Immunotherapy, Shizuoka Cancer Center Research Institute, 1007 Shimonagakubo, Nagaizumi-cho, Sunto-gun, Shizuoka 411-8777, Japan

E-mail: y.akiyama@scchr.jp

Abbreviations: ; ADCC, antibody-dependent cellular cytotoxicity; B7-H4, B7 family homolog 4; Ab, antibody

Key words: B7-H4, B7 family, immune checkpoint, indirect ADCC, gene expression profiling

\section{Introduction}

T-cell dependent tumor immune responses have been demonstrated in clinical studies and the CD28 family of receptors and the $\mathrm{B} 7$ family of ligands are thought to be most attractive as T-cell regulatory targets for cancer immunotherapy or for the control of immunological disorders (1-4). B7 homolog 4 (B7-H4) negatively regulates T-cell proliferation and cytokine production $(5,6)$. B7-H4 mRNA is expressed widely in multiple tissues to a low degree $(6,7)$, but its receptor on activated lymphocytes has yet to be identified $(8,9)$.

B7-H4 is overexpressed in many human cancers (10-13), and $\mathrm{B} 7-\mathrm{H} 4$ levels in patient sera are upregulated in ovarian cancer and renal cell carcinoma (RCC) $(14,15)$. However, low levels of B7-H4 can also be detected in healthy human sera. Endothelial cells of the RCC tumor vasculature express B7-H4, whereas normal renal vessels and tissues exhibit little to no expression. Notably, patients with RCC expressing both B7-H1 and B7-H4 have a poor prognosis compared to patients presenting with single expression alone or patients with no expression at all (12). By contrast, high expression of B7-H4 in breast cancer is correlated with an improved recurrence-free survival (16).

Ovarian cancer patients frequently express the B7-H4 ligand in the cytoplasm and on membranes but not on the cell surface $(17,18)$, and the expression level is inversely correlated with patient survival (19). However, B7-H4-expressing infiltrating macrophages, but not tumor cells, suppress tumorassociated antigen (TAA)-specific T-cell immunity (18). Tumor cell-derived B7-H4 could function in immunosuppression even though the physiological implications are not apparent.

IL-6 and IL-10 induce B7-H4 expression on tumor-associated macrophages (TAMs) and on other immune cells involved in Treg development $(18,19)$, but IL-6 and IL-10 receptors rarely exist on normal tissue cells (20) and non-hematopoietic malignanct cell lines (21), which indicates that B7-H4 expression in tumor cells is regulated in a different manner than in immune cells. By contrast, IFN- $\gamma$ induces B7-H4 expression on mouse embryonic fibroblasts (16), and its receptor is widely expressed on both normal and tumor cells. This indicates that IFN- $\gamma$ is prossibly a B7-H4 inducer in tumors. Consequently, 
ovarian cancer rapidly loses B7-H4 expression after a few days in vitro, which suggests that the microenvironment can influence B7-H4 expression (22).

B7-H4 is a candidate immunoregulatory target and may also be a direct therapeutic target against tumors. B7-H4 knockdown by morpholino oligos improved TAA-specific T-cell immunity (18) and knockout protected mice from experimental lung metastasis (23). However, antibodydependent cellular cytotoxicity (ADCC) or tumor growth suppression was not reported except during B7-H4 forced expression (11). Notably, Lee et al reported that B7-H4 is not detected on immune cells of either humans or mice by flow cytometry before or even after stimulation, and this observation is inconsistent with previous studies (24).

In clinical studies targeting immune checkpoint molecules of the B7/CD28 families, a B7-H1 (PD-L1)-targeting inhibitory antibody has shown potent antitumor effects in advanced melanoma (3), although B7-H4-targeting clinical trials have not yet been performed.

In this study, we performed comprehensive whole exome sequencing and gene expression profiling based on 1,058 cancer patient-derived tumor tissues and consequently found high B7-H4 expression in non-small cell lung cancer and breast cancer patients. Furthermore, we characterized unstable expression of the $\mathrm{B} 7-\mathrm{H} 4$ molecule in cancer cells using antibodies generated in house. Finally, we discuss how to use anti-B7-H4 antibodies for cancer immunotherapy.

\section{Materials and methods}

Patient materials. This clinical research project using comprehensive whole exome sequencing and gene expression profiling of various tumor tissues, called the High-tech Omicsbased Patient Evaluation (HOPE) for Cancer Therapy, has been conducted in accordance with the 'Ethical Guidelines for Human Genome and Genetic Analysis Research', revised in 2013. Informed consents were obtained from all patients participating in the HOPE project, which was approved by the Institutional Review Board of the Shizuoka Cancer Center (SCC), Japan. Tumor tissues, along with surrounding normal tissues, were dissected from surgical specimens by trained pathologists.

Animal experiments. BALB/cA mice and nude mice (BALB/cA-nu/nu) were obtained from Nippon Clea (Tokyo, Japan). All animals were cared for and used humanely according to the Guidelines for the Welfare and Use of Animals in Cancer Research (25). All procedures were approved by the Animal Care and Use Committee of the Shizuoka Cancer Center (SCC) Research Institute.

Gene expression analysis of the B7 family of genes. Total RNA was extracted from $\sim 10 \mathrm{mg}$ of tissue samples using the miRNeasy Mini Kit (Qiagen) according to the manufacturer's instructions. Following assessment using an Agilent 2100 Bioanalyzer (Agilent Technologies, Santa Clara, CA, USA), total RNA with an RNA integrity number (RIN) of six or higher was used for DNA microarray analysis. Gene expression analysis was performed using SurePrint G3 Human GE 8x60K v2.0 arrays (Agilent Technologies) according to the manufac- turer's instructions. Signal data analysis was carried out using GeneSpring version 13.1.1 software (Agilent Technologies). The ratio of tumor tissue vs. surrounding non-cancerous tissue was calculated from the normalized values.

Generation of anti-B7-H4 monoclonal antibodies. The human B7-H4 isoform 1 extracellular domain was constructed with a $6 \mathrm{X}$ histidine tag in a pcDNA3.3 expression vector, and the B7-H4 extracellular soluble free form was harvested from Expi293F ${ }^{\mathrm{TM}}$ cell (Life Technologies Corporation) culture supernatant, affinity-purified, and used for experiments. B7-H1 and B7-DC were produced in the same way for use as negative controls. After the immunization of BALB/cA mice, an antibody secreting hybridoma was generated by a common method using the mouse myeloma cell line P3X63Ag8.653 (American Type Culture Collection; ATCC, Manassas, VA, USA).

ELISA. Specificity was validated by sandwich ELISA and fluorescent staining of B7-H4-transfected HEK293 cells. Briefly, purified newly-generated antibodies were immobilized on a 96-well microplate Nunc Immobilizer Amino Surface (Thermo Fisher Scientific, Inc.) prior to the addition of $3 \%$ bovine serum albumin for overnight blocking and $10 \mu \mathrm{g} / \mathrm{ml}$ B7-H4 (soluble form) or controls. After being washed, $2 \mu \mathrm{g} / \mathrm{ml}$ biotinylated antibody (Ab) clone \#25 was added and detected by HRP-conjugated streptavidin (Thermo Fisher Scientific, Inc.).

Flow cytometry. HEK293 cells that transformed with the full B7-H4 sequence or cancer cell lines were incubated with $8 \mu \mathrm{g} /$ $\mathrm{ml} \mathrm{Ab}$ clones and later incubated with $4 \mu \mathrm{g} / \mathrm{ml}$ PE-labeled polyclonal anti-mouse Ig Ab (BD Biosciences) on ice. Fluorescence intensity was determined by the flow cytometer FACSCanto (BD Biosciences).

Affinity kinetics determination of anti-B7-H4 antibodies. Surface plasmon resonance (SPR) analysis was performed on a Biacore X100 (GE Healthcare) in order to determine the kinetics of the anti-B7-H4 Ab and free form of B7-H4. All reagents and sensor chips were purchased from GE Healthcare. Immobilization of anti-B7-H4 IgG antibodies on the CM5 sensor chip was performed at $\mathrm{pH}$ 5.0, and the Ab binding was targeted to 1000 response units (RU). To regenerate the sensor chip, $10 \mathrm{mM}$ glycine- $\mathrm{HCl} \mathrm{pH} 1.7$ was used. The binding kinetics were monitored by injecting multiple concentrations of B7-H4 in HBS buffer (10 mM HEPES pH 7.4, containing $0.15 \mathrm{M} \mathrm{NaCl}, 3 \mathrm{mM}$ EDTA, and $0.05 \%$ Tween-20) at a flow rate of $30 \mu \mathrm{l} / \mathrm{min}$ at $25^{\circ} \mathrm{C}$. The dissociation phase was also monitored by HBS buffer flow. The binding kinetic parameters were calculated by Biacore X100 evaluation software.

Western blot analysis. Breast cancer cell line lysates harvested with Laemmli sample buffer, and over-confluent culture supernatants were used for western blot analysis. Cell lysates and supernatants were electrophoresed through a SDS-PAGE gradient gel and transferred to a PVDF membrane. After overnight blocking with 5\% skim milk and washing with $0.05 \%$ Tween-20-PBS (T-PBS), the membrane was incubated for $1 \mathrm{~h}$ at room temperature (RT) with rabbit anti-human $\mathrm{B} 7-\mathrm{H} 4 \mathrm{Ab}$ 
(clone, EP1165). After being washed with T-PBS, the membrane was incubated with a secondary Ab, HRP-conjugated donkey anti-rabbit IgG polyclonal Ab (GE Healthcare) diluted 1:10,000. ECL Plus (GE Healthcare) was used for detection according to the manufacturer's instructions.

Immunohistochemistry. Female nude mice (BALB/cA-nu/nu, 5-6 weeks old) were transplanted subcutaneously with human breast cancer MDA-MB-468 or lung cancer NCI-H2170 cells. Formalin-fixed paraffin-embedded (FFPE) cancer tissue blocks were made. To evaluate B7-H4 expression, sections from the cancers were immunostained with anti-B7-H4 Ab (clone \#25) or mouse IgG1 isotype control (BD Pharmingen) and later stained with hematoxylin.

Tumor growth inhibition assay. MDA-MB-468 cells $\left(1 \times 10^{7}\right)$ were inoculated into the mammary fat pad of BALB/cA-nu/nu mice. Antibody clone \#25, at doses of 2 or $10 \mathrm{mg} / \mathrm{kg}$, was administered by intraperitoneal injection twice a week from day 9 to day 27 after tumor inoculation. To evaluate the antitumor activity against inoculated tumors, tumor volume was calculated based on the National Cancer Institute formula as follows: Tumor volume $\left(\mathrm{mm}^{3}\right)=$ length $(\mathrm{mm}) \times$ width $\left.(\mathrm{mm})\right]^{2} \times 1 / 2$.

Indirect ADCC experiment. Briefly, effector cells were isolated from healthy volunteer peripheral blood by Ficoll-Paque PLUS (GE Healthcare Life Sciences, Buckinghamshire, UK) and then enriched by depletion of $\mathrm{CD} 14^{+}$or $\mathrm{CD} 19^{+}$cells using MicroBeads and autoMACS (Miltenyi Biotec K.K., Tokyo, Japan). The effector cells were incubated on ice for $10 \mathrm{~min}$ with $0.2 \mathrm{mg} / \mathrm{ml}$ (high concentration) anti-CD3 Ab (OKT3) diluted with staining buffer $(0.5 \%$ BSA, $0.1 \%$ azide, $1 \mathrm{mM}$ glucose-PBS), followed by washing. Cells were then incubated with $0.5 \mathrm{mg} / \mathrm{ml}$ polyclonal rabbit anti-mouse immunoglobulins (DakoCytomation, Glostrup, Denmark) and after being washed, they were incubated with $0.5 \mathrm{mg} / \mathrm{ml}$ of each anti-B7-H4 antibody. The effector cells were washed and resuspended to a concentration of $\sim 10^{7}$ cells $/ \mathrm{ml}$ in 10\% FBS-RPMI-1640 and co-cultured with non-radioactive reagent-labeled MDA-MB468 target cells in a 96 -well round-bottom plate at $37^{\circ} \mathrm{C}$ for $3 \mathrm{~h}$. Target cell lysis was performed with DELFIA ${ }^{\circledR}$ EuTDA Cytotoxicity Assay Reagents and measured using a Wallac 1420 ARVO SX multilabel counter (PerkinElmer, Waltham, MA, USA). The percentage of specific lysis was determined by the following formula: Percentage of specific lysis $=($ experimental release - spontaneous release $) /($ maximal release - spontaneous release) x 100 .

Statistical analysis. Statistically differences were analyzed using the Student's paired two-tailed t-test. Values of $\mathrm{P}<0.01$ were considered to indicate statistically significant differences.

\section{Results}

B7-H4 expression in cancer tissues and cell lines. We found that B7-H4 expression was upregulated in some types of cancer when compared to expression in non-cancerous normal tissues (Fig. 1). B7-H4 expression was upregulated in breast, lung, and gynecological cancers and downregulated in skin and urinary tract cancers. Expression of other genes from the

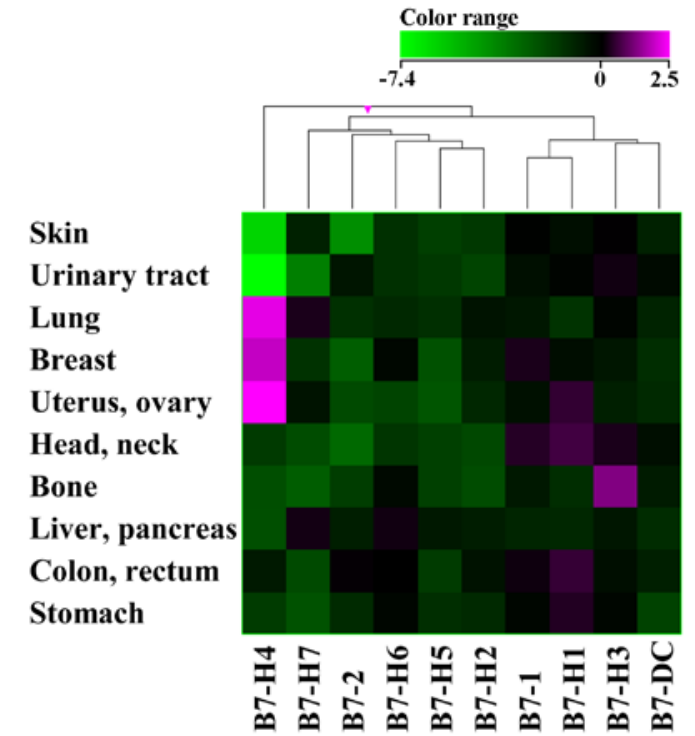

Figure 1. Altered B7 homolog 4 (B7-H4) gene expression was detected in cancer tissues. Unsupervised hierarchical clustering of gene expression of the B7 family homologs was performed in cancer tissues derived from 1,053 patients. The cancer in the organs of over 10 patients are indicated on the left. Relative expression of each tumor tissue vs. surrounding non-cancerous tissue was calculated from normalized values. The colors indicate the average of each group (-7.4 to $+2.2 \log 2$ range). Data analysis was performed using GeneSpring version 13.1.1.

B7 family was not apparently altered. B7-H4 expression was detected in breast and ovarian cancer cell lines by RT-PCR in accordance with the previous study (data not shown), but the soluble free form of B7-H4 in the culture medium was not, as determined by ELISA. The splice variants of B7-H4 that were detected corresponded mainly to isoforms 1,2 , and 4 and partially to isoform 3 which has a different sequence.

Production and characterization of anti-B7-H4 monoclonal antibodies. We generated 19 hybridoma clones of anti-human B7-H4 isoform 1 for detection of the natural form, and purified eight antibody clones which could be cultured in vitro under serum-free conditions. The antibody clones bound B7-H4 but not B7 homologs PD-L1 or PD-L2 (B7-DC) (Fig. 2A), and the staining of HEK293 cells transfected with the full B7-H4 isoform 1 sequence showed two different types of staining, strong (\#18, \#25) and weak (\#113, \#121, \#209), by flow cytometry. All mAb clones were confirmed to have different DNA sequences (Fig. 2B).

B7-H4 forms homodimers. Sandwich ELISAs using antibody clone \#25 as both the capture and detector antibody detected the free form of B7-H4; ELISA using clone \#18 as the capture Ab showed a similar curve. These two capture Abs had lower sensitivities than the other clones, which contrasted to staining of HEK293 transfectants (Figs. 3A and 2B). B7-H4 is a monovalent molecule, and thus these observations were indicative of B7-H4 homodimerization and bivalent antigenicity. In determining the affinity kinetics of the antibodies to the free form of B7-H4, both clone \#25 and the commercially available clone-H74 showed two-state reaction curves, including rapid dissociation and stable dissociation curves, which can be explained by dimer dissociation and monomer 
A

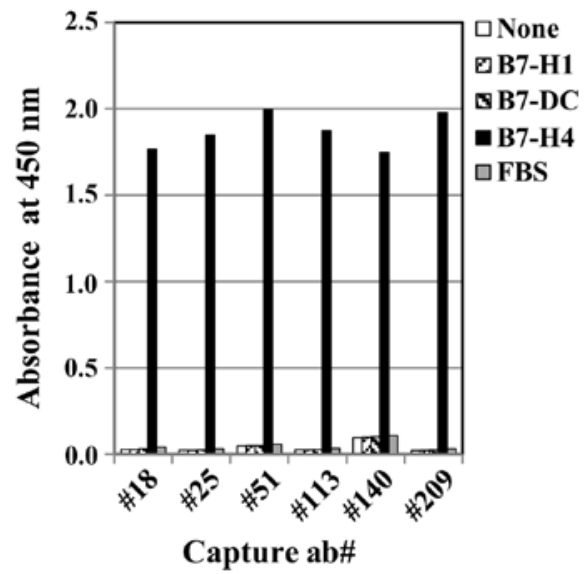

B
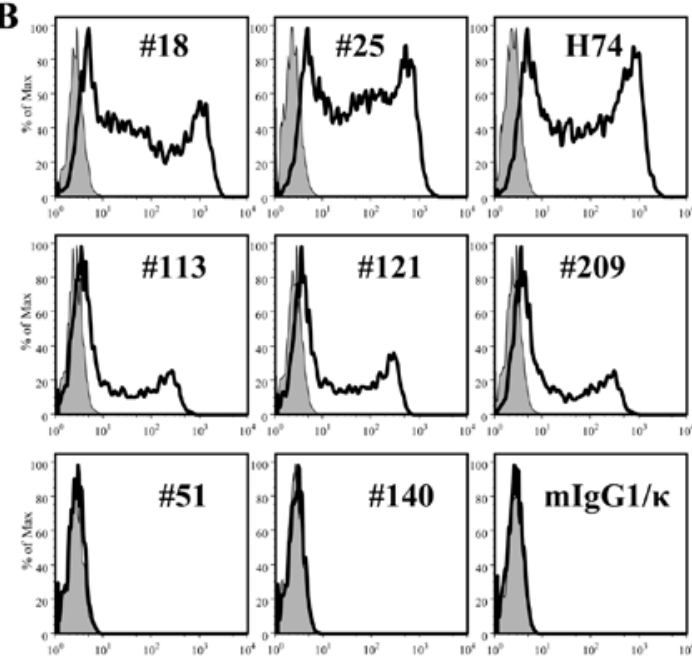

Anti-mouse Ig Ab-PE (2 $\left.{ }^{\text {nd }} \mathbf{A b}\right)$

Figure 2. The specificity of the newly generated antibodies is validated. (A) Each newly generated antibody was immobilized on a 96-well microplate as the capture antibody and biotinylated clone \#25 Ab was used as the detector antibody. In addition to B7 homolog 4 (B7-H4), B7-H1 (PD-L1) and B7-DC (PD-L2) were used as controls. (B) The full gene sequence of B7-H4 was transfected into HEK293 cells and stained with the antibody clones or commercially available control antibodies (bold line: B7-H4 full sequence transformed, filled line: control vector transformed). Cells were then stained with secondary immunofluorescently labeled anti-mouse IgG antibody. These newly generated antibody clones are IgG, while clones \#25, \#113 and \#209 are IgG1.

A

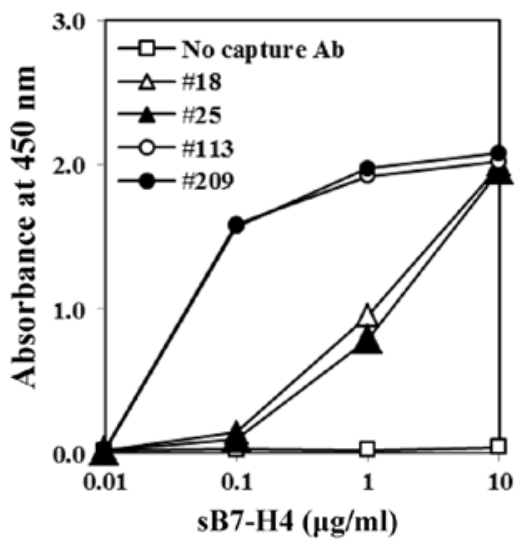

B

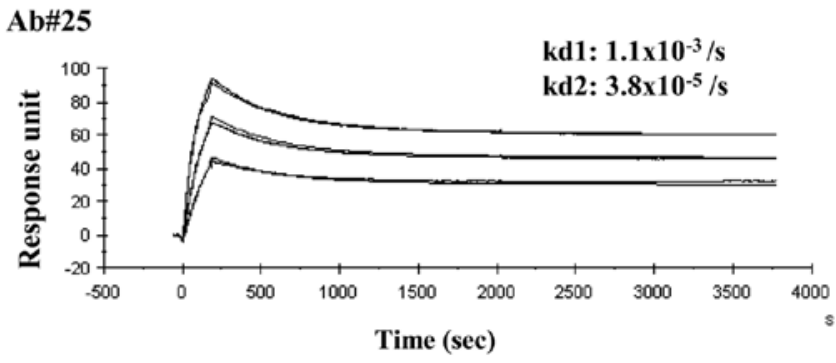

H74

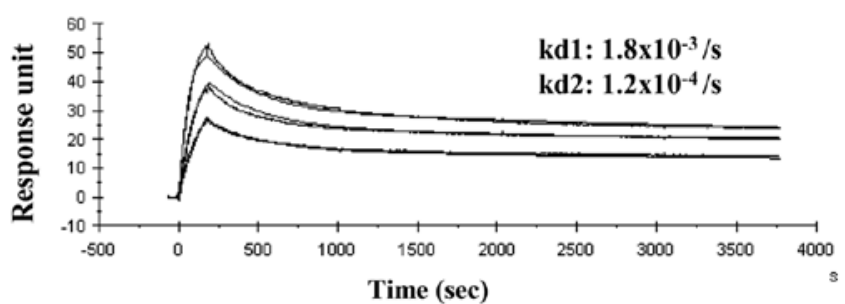

Figure 3. B7 homolog 4 (B7-H4) forms homodimers. (A) Newly-generated antibodies were used as capture antibodies and biotinylated clone \#25 antibody was used for detecting B7-H4. Both clone \#25 pairs could detect monovalent B7-H4. (B) Surface plasmon resonance (SPR) analysis was performed on a Biacore X100 (GE Healthcare) to determine the kinetics of the anti-B7-H4 antibody and the extracellular free form of B7-H4. Clone \#25 antibody and the commercially available $\mathrm{H} 74$ antibody gave two-state reaction curves when tested against B7-H4. The higher dissociation rates are nearly identical.

dissociation, respectively (Fig. 3B). Each rapid dissociation rate was equivalent.

B7-H4 ligand instability on the tumor cell surface. B7-H4 expression in the breast cancer cell lines was validated by western blot analysis. Predicted molecular weight of B7-H4 is $29 \mathrm{kDa}$ but it aligns with a size of $50 \sim 70 \mathrm{kDa}$ owing to glycosylation and isoform variations $(14,26)$. B7-H4 was detected in cell lysates but not in culture supernatants (Fig. 4A). The soluble-free forms have reportedly been detected in patient sera, but it is difficult to detect in vitro in culture supernatant.
We compared B7-H4 staining in the MDA-MB 468 cell line under suppressive (azide-containing at $4^{\circ} \mathrm{C}$ ) or normal (azide-free at RT) conditions by flow cytometry (Fig. 4B). B7-H4 staining was positive under suppressive conditions using clone \#18 and clone \#25 antibodies; however, there was no detection under normal conditions. In addition, B7-H4 staining was also not apparent in samples that underwent an overnight incubation at $37^{\circ} \mathrm{C}$ and $5 \% \mathrm{CO}_{2}$.

In vivo experiments. In the MDA-MB-468 transplanted nude mouse model, the strong B7-H4 expression on the tumor cell 
A

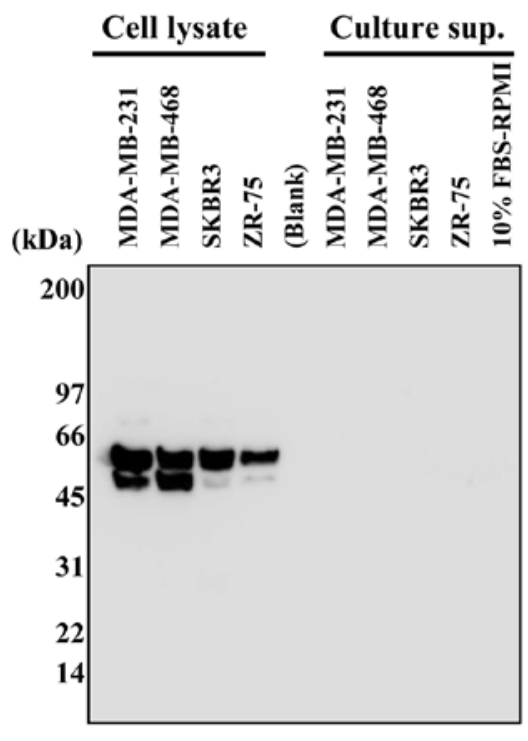

B
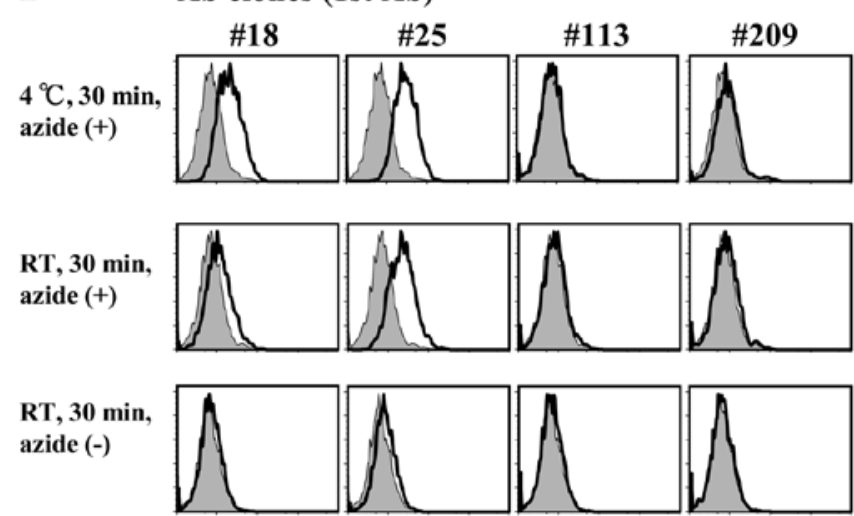

$37^{\circ} \mathrm{C}, 18 \mathrm{~h}$, culture condition

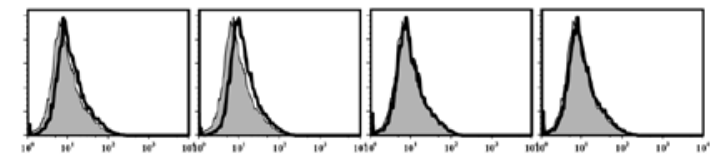

Anti-mouse Ig Ab-PE (2 ${ }^{\text {nd }}$ Ab)

Figure 4. The B7 homolog 4 (B7-H4) ligand is unstable on the tumor cell surface. (A) B7-H4 expression of breast cancer cells was validated by western blot analysis. B7-H4 was detected in cell lysates but not in cell culture supernatants. (B) Breast cancer cell line MDA-MB-468 was incubated first with $10 \mu \mathrm{g} / \mathrm{ml}$ antibody clones under each of the indicated conditions and then stained with a fluorescently labeled secondary antibody. B7-H4 was lost from the cell surface under room temperature or $37^{\circ} \mathrm{C}$ culture conditions.

A

\section{MDA-MB-468}

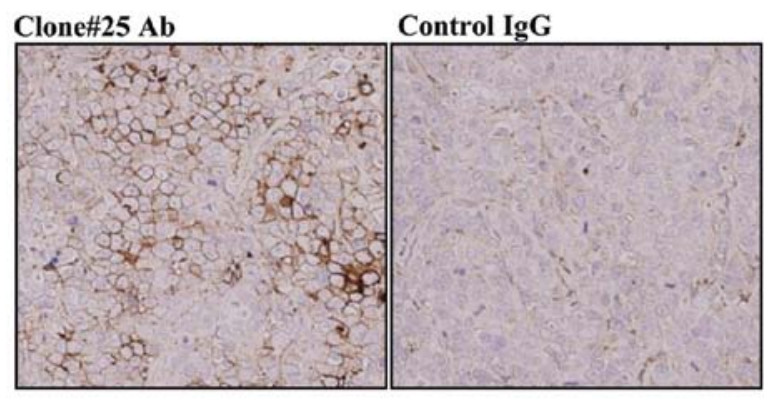

\section{NCI-H2170}

Clone\#25 Ab

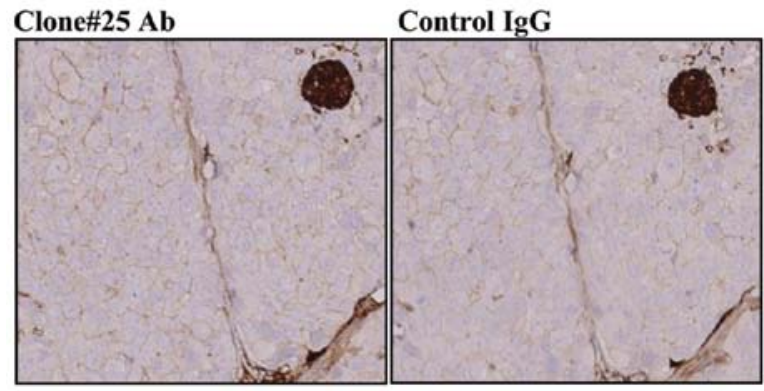

B

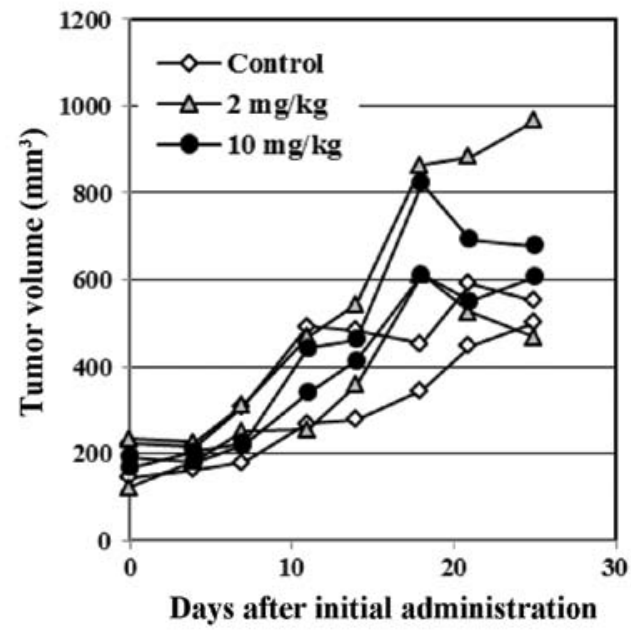

Figure 5. Anti-B7-H4 antibody is not capable of suppressing tumor growth. Human breast cancer MDA-MB-468 and lung cancer NCI-H2170 cells were inoculated into the flank of BALB/cA-nu/nu mice. (A) Formalin-fixed paraffin-embedded (FFPE) tissues of transplanted tumor tissues were stained with clone \#25 antibody and hematoxylin. (B) Clone \#25 antibody at doses of 2 and $10 \mathrm{mg} / \mathrm{kg}$ was administered twice a week beginning one week after tumor inoculation. Tumor growth in each mouse is shown. B7-H4, B7 homolog 4 .

membrane was observed by immunohistochemistry (IHC), and the intensity of the staining was heterogeneous in the tumor tissue (Fig. 5A). By contrast, the B7-H4-negative NCI-H2170 cell line (control) did not show any B7-H4 expression in tumor tissues. We administered antibody clone \#25 (mouse IgG1) to the MDA-MB-468 transplanted mouse model, but no tumor suppressive effect was observed (Fig. 5B).

Indirect ADCC elicited tumor cell death. Based on the observations that i) there was loss of $\mathrm{B} 7-\mathrm{H} 4$ expression on 
A

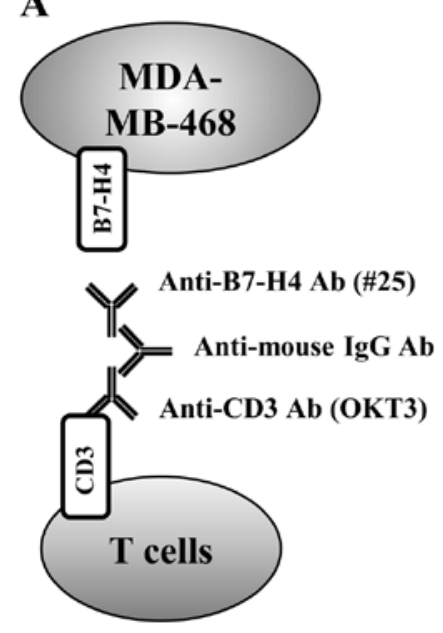

B

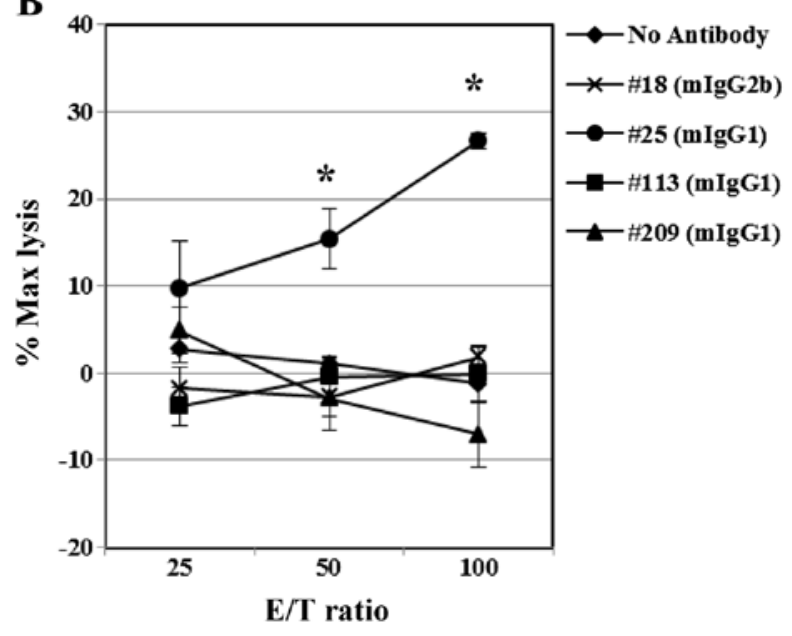

Figure 6. Indirect ADCC-elicited tumor cell death. (A) Enriched human T cells were linked to anti-B7-H4 antibody using anti-CD3 antibody (OKT3 clone) and polyclonal anti-mouse IgG antibody. The effector cells were co-cultured with labeled MDA-MB-468 target cells in 96 -well round-bottom plates at $37^{\circ} \mathrm{C}$ for 3 h. (B) Target cell lysis was assessed using the DELFIA non-radioactive cytotoxicity assay. Data are indicated as mean \pm SE and are representative of three independent experiments. " $\mathrm{P}<0.01$ vs. no anti-B7-H4 Ab. ADCC, antibody-dependent cellular cytotoxicity; B7-H4, B7 homolog 4.

the tumor cell surfaces under usual conditions and ii) there was lack of antitumor activity due to non-functional ADCC in vivo, we employed an indirect ADCC-redirecting T-cell cytotoxicity assay to study B7-H4 using polyclonal anti-mouse IgG-mediated linking of anti-CD3 and anti-B7-H4 antibodies. Freshly enriched $\mathrm{T}$ cells indirectly targeting B7-H4 exhibited clone \#25-dependent cellular cytotoxicity against the MDA-MB468 cells (Fig. 6). By contrast, clones \#18 (mIgG2b), \#113 (mIgG1) and \#209 (mIgG1) did not induce targeted cell death.

\section{Discussion}

A comprehensive whole exome sequencing and gene expression analysis of surgically resected tumor tissues derived from 2,000 patients registered in the HOPE project was performed by the Shizuoka Cancer Center (SCC), Japan over the last 2 years. Focusing on the B7 and CD28 gene families, we found that B7-H4 was altered in several types of cancer (Fig. 1). Unlike other B7 family genes, B7-H4 is also expressed in many normal tissues at the mRNA level. B7-H4 expression in cancer cell lines is low level except for ovarian and breast cancers, while mammary gland epithelium normally expresses B7-H4 (14,20). In vitro-cultured cell lines reflect a similar $\mathrm{B} 7-\mathrm{H} 4$ expression profile as in normal tissues, but expression is not comparable to that of lung cancer tissues in vivo because of B7-H4 modulation.

Our monoclonal antibody clones \#113 and \#209 bound to B7-H4-transfected HEK293 cells but not to the breast cancer cell line MDA-MB-468 expressing B7-H4 (Figs. 2A and 4B). No B7-H4 gene mutations in the MDA-MB-468 cell line were found, so we hypothesized that the natural expression possibly harbors some type of antibody-binding site as a result of homodimer or heterodimer formation on the cell surface. In addition, we observed that B7-H4 intensity varied as a result of staining temperature and cellular activity (Fig. 4B). Considering that B7-H4 was not identified in culture supernatants (Fig. 4A), tumor cell surface-expressed B7-H4 is likely internalized. The B7-H4 molecule consists of merely two amino acids in the cytoplasm and does not have any signaling function. B7-H4 may be involved in immune regulation as a ligand or decoy ligand for receptors, or it may form a heterodimer with other known B7 family ligands (27). B7-H4 nuclear localization was reported (28), but the expressed isoforms and constructs appear to mainly function on the cell membrane to regulate intercellular signaling.

The studies concerning B7-H4 expression on tumor tissues are not consistent, which may be explained partially by incompatible antibody use (29). However, differences in expression on immune cells suggest immune receptor mobility such as the TCR, CD19 and CD28 families; cross-linking of these antibodies could easily result in receptor internalization on activated lymphocytes (30-33). The disappearance of B7-H4 on immune cells may be due to the cross-linking of antibodies (24). Mobility of the B7-H4 ligand on tumor cells was not accounted for (Fig. 4B) and puzzled expression in ovarian cancer $(17,18)$ may explain this phenomenon. This may therefore explain why ADCC could not be performed on tumor cells naturally expressing B7-H4 (Fig. 5B).

The B7-H4 antibody was able to induce cytotoxicity of tumor cells expressing hB7-H4 or mB7-H4 by retroviral vectors through ADCC or complement-dependent cytotoxicity (11), but these observations have not been demonstrated in tumors spontaneously expressing B7-H4. We examined whether the clone \#25 Ab could act for MDA-MB-468 tumors transplanted in nude mice, but tumor growth was not suppressed, despite B7-H4 expression in tumors in vivo (Fig. 5A). This is possibly the result of antigen disappearance on the cell surface (Fig. 4B). Cancer therapy targeting immune regulatory molecules are difficult to test in a mouse model, and the benefit of targeting human B7-H4 in human tumors has not yet been shown. In addition, GPI-anchored glycine in mouse B7-H4 is not conserved in humans, and thus B7-H4 may not behave similarly in mice and humans (6). Recently, single-chain Fv fragments (scFv) against hB7-H4 were reported but did not exhibit tumor growth suppression in vivo. Small molecule 
antibodies such as scFv leak through the kidneys (34-36), and decreased affinity of scFv $(37,38)$ may be incompatible with this inhibitory effect.

Dynamic and unstable cell surface antigens are probably not a target of conventional ADCC activity, but by redirecting T-cell cellular cytotoxicity using specific antibodies recognizing cell surface CD19 antigens instead of a peptide/MHC complex and T-cell clonal specificity (39) have been successful. Clinical studies of chimeric antigen receptor (CAR) $\mathrm{T}$ cells transfected with the CD3 gene linked to antigen-specific scFv have been successful and extended further to other tumor targets. Bispecific scFv linked to CD19 and CD3 was also succeeded in clinical study (40).

Here, we used indirect ADCC assays targeting B7-H4 (Fig. 6) and demonstrated a clone \#25 Ab-dependent cellular cytotoxicity in breast cancer cells. Since clone \#25 (mouse IgG1) does not bind to human Fc receptors, this tumor lysis appears to result from effector $\mathrm{T}$ cells but not natural killer cells. Ab clone \#18 (IgG2b) and others that bound to B7-H4 on HEK293 cells did not induce breast cancer cell death in this study. These observations are the first to report anti-B7H4 Ab-mediated ADCC activity against tumors spontaneously expressing B7-H4. Therefore, anti-B7H4 $\mathrm{Ab}$-mediated cell death may be considered an alternative therapy for PD-L1-negative and B7H4-positive cancers.

B7-H4 upregulation in lung cancer tissues (Fig. 1) could be induced by cytokines secreted from tumor-infiltrating lymphocytes or by the accumulation of B7-H4-expressing suppressive macrophages derived from abundant intrinsic alveolar-associated macrophages $(41,42)$. In cancer, tumor-infiltrating macrophages and regulatory $\mathrm{T}$ cells collectively suppress tumor-associated antigen-specific $\mathrm{T}$ cells via B7-H4 and consequently protect tumor cells from immune attacks $(18,22)$. Therefore, approaches to targeting immune suppressor cells expressing B7-H4 are needed for effective cancer therapy, in addition to targeting tumor cells. Elimination of B7-H4-expressing tumor cells and immune-suppressive macrophages by redirecting cytotoxic $\mathrm{T}$ cells could be a novel approach for next-generation therapies against cancer.

\section{Acknowledgements}

This study was supported by a grant to Yasuto Akiyama by JSPS KAKENHI (grant no. 25430166), Japan.

\section{References}

1. Hodi FS, O'Day SJ, McDermott DF, Weber RW, Sosman JA, Haanen JB, Gonzalez R, Robert C, Schadendorf D, Hassel JC, et al: Improved survival with ipilimumab in patients with metastatic melanoma. N Engl J Med 363: 711-723, 2010.

2. Hamid O, Robert C, Daud A, Hodi FS, Hwu WJ, Kefford R Wolchok JD, Hersey P, Joseph RW, Weber JS, et al: Safety and tumor responses with lambrolizumab (anti-PD-1) in melanoma. N Engl J Med 369: 134-144, 2013.

3. Brahmer JR, Tykodi SS, Chow LQ, Hwu WJ, Topalian SL, Hwu P, Drake CG, Camacho LH, Kauh J, Odunsi K, et al: Safety and activity of anti-PD-L1 antibody in patients with advanced cancer. N Engl J Med 366: 2455-2465, 2012.

4. Rizvi NA, Hellmann MD, Snyder A, Kvistborg P, Makarov V, Havel JJ, Lee W, Yuan J, Wong P, Ho TS, et al: Cancer immunology. Mutational landscape determines sensitivity to PD-1 blockade in non-small cell lung cancer. Science 348: 124-128, 2015.
5. Sica GL, Choi IH, Zhu G, Tamada K, Wang SD, Tamura H, Chapoval AI, Flies DB, Bajorath J and Chen L: B7-H4, a molecule of the B7 family, negatively regulates $\mathrm{T}$ cell immunity. Immunity 18: 849-861, 2003

6. Prasad DV, Richards S, Mai XM and Dong C: B7S1, a novel $\mathrm{B} 7$ family member that negatively regulates $\mathrm{T}$ cell activation. Immunity 18: 863-873, 2003.

7. Zang X, Loke P, Kim J, Murphy K, Waitz R and Allison JP: B7x: a widely expressed B7 family member that inhibits $T$ cell activation. Proc Natl Acad Sci USA 100: 10388-10392, 2003.

8. Chen L: Co-inhibitory molecules of the B7-CD28 family in the control of T-cell immunity. Nat Rev Immunol 4: 336-347, 2004.

9. Pardoll DM: The blockade of immune checkpoints in cancer immunotherapy. Nat Rev Cancer 12: 252-264, 2012.

10. Choi IH, Zhu G, Sica GL, Strome SE, Cheville JC, Lau JS, Zhu Y, Flies DB, Tamada K and Chen L: Genomic organization and expression analysis of B7-H4, an immune inhibitory molecule of the B7 family. J Immunol 171: 4650-4654, 2003.

11. Jeon H, Vigdorovich V, Garrett-Thomson SC, Janakiram M, Ramagopal UA, Abadi YM, Lee JS, Scandiuzzi L, Ohaegbulam KC, Chinai JM, et al: Structure and cancer immunotherapy of the B7 family member B7x. Cell Reports 9: 1089-1098, 2014

12. Krambeck AE, Thompson RH, Dong H, Lohse CM, Park ES Kuntz SM, Leibovich BC, Blute ML, Cheville JC and Kwon ED: B7-H4 expression in renal cell carcinoma and tumor vasculature: Associations with cancer progression and survival. Proc Natl Acad Sci USA 103: 10391-10396, 2006.

13. Miyatake T, Tringler B, Liu W, Liu SH, Papkoff J, Enomoto T, Torkko KC, Dehn DL, Swisher A and Shroyer KR: B7-H4 (DD-O110) is overexpressed in high risk uterine endometrioid adenocarcinomas and inversely correlated with tumor T-cell infiltration. Gynecol Oncol 106: 119-127, 2007.

14. Simon I, Zhuo S, Corral L, Diamandis EP, Sarno MJ, Wolfert RL and Kim NW: B7-h4 is a novel membrane-bound protein and a candidate serum and tissue biomarker for ovarian cancer. Cancer Res 66: 1570-1575, 2006.

15. Thompson RH, Zang X, Lohse CM, Leibovich BC, Slovin SF, Reuter VE, Cheville JC, Blute ML, Russo P, Kwon ED, et al: Serum-soluble B7x is elevated in renal cell carcinoma patients and is associated with advanced stage. Cancer Res 68: 6054-6058, 2008.

16. Rahbar R, Lin A, Ghazarian M, Yau HL, Paramathas S, Lang PA, Schildknecht A, Elford AR, Garcia-Batres C, Martin $\mathrm{B}$, et al: B7-H4 expression by nonhematopoietic cells in the tumor microenvironment promotes antitumor immunity. Cancer Immunol Res 3: 184-195, 2015.

17. Zang X, Sullivan PS, Soslow RA, Waitz R, Reuter VE, Wilton A, Thaler HT, Arul M, Slovin SF, Wei J, et al: Tumor associated endothelial expression of B7-H3 predicts survival in ovarian carcinomas. Mod Pathol 23: 1104-1112, 2010.

18. Kryczek I, Zou L, Rodriguez P, Zhu G, Wei S, Mottram P, Brumlik M, Cheng P, Curiel T, Myers L, et al: B7-H4 expression identifies a novel suppressive macrophage population in human ovarian carcinoma. J Exp Med 203: 871-881, 2006.

19. Kryczek I, Wei S, Zhu G, Myers L, Mottram P, Cheng P, Chen L, Coukos G and Zou W: Relationship between B7-H4, regulatory T cells, and patient outcome in human ovarian carcinoma. Cancer Res 67: 8900-8905, 2007.

20. National Cancer Institute: Genotype-Tissue Expression (GTEx) http://www.gtexportal.org/home. (2015).

21. Broad institute: The Cancer Cell Line Encyclopedia (CCLE) https://www.broadinstitute.org/ccle/home. (2015).

22. Dangaj D, Lanitis E, Zhao A, Joshi S, Cheng Y, Sandaltzopoulos R, Ra HJ, Danet-Desnoyers G, Powell DJ Jr and Scholler N: Novel recombinant human b7-h4 antibodies overcome tumoral immune escape to potentiate T-cell antitumor responses. Cancer Res 73: 4820-4829, 2013.

23. Abadi YM, Jeon H, Ohaegbulam KC, Scandiuzzi L, Ghosh K, Hofmeyer KA, Lee JS, Ray A, Gravekamp C and Zang X: Host b7x promotes pulmonary metastasis of breast cancer. J Immunol 190: 3806-3814, 2013.

24. Lee JS, Scandiuzzi L, Ray A, Wei J, Hofmeyer KA, Abadi YM, Loke P, Lin J, Yuan J, Serreze DV, et al: B7x in the periphery abrogates pancreas-specific damage mediated by self-reactive CD8 T cells. J Immunol 189: 4165-4174, 2012.

25. Workman P, Aboagye EO, Balkwill F, Balmain A, Bruder G, Chaplin DJ, Double JA, Everitt J, Farningham DAH, Glennie MJ, et al: Guidelines for the welfare and use of animals in cancer research. Br J Cancer 102: 1555-1577, 2010. 
26. Tringler B, Zhuo S, Pilkington G, Torkko KC, Singh M, Lucia MS, Heinz DE, Papkoff J and Shroyer KR: B7-h4 is highly expressed in ductal and lobular breast cancer. Clin Cancer Res 11: 1842-1848, 2005.

27. Butte MJ, Keir ME, Phamduy TB, Sharpe AH and Freeman GJ: Programmed death-1 ligand 1 interacts specifically with the B7-1 costimulatory molecule to inhibit $\mathrm{T}$ cell responses. Immunity 27 : $111-122,2007$.

28. Zhang L, Wu H, Lu D, Li G, Sun C, Song H, Li J, Zhai T, Huang L, Hou C, et al: The costimulatory molecule B7-H4 promote tumor progression and cell proliferation through translocating into nucleus. Oncogene 32: 5347-5358, 2013.

29. Smith JB, Stashwick C and Powell DJ Jr: B7-H4 as a potential target for immunotherapy for gynecologic cancers: A closer look. Gynecol Oncol 134: 181-189, 2014.

30. Pulczynski S, Boesen AM and Jensen OM: Antibody-induced modulation and intracellular transport of CD10 and CD19 antigens in human B-cell lines: An immunofluorescence and immunoelectron microscopy study. Blood 81: 1549-1557, 1993.

31. Gerber HP, Kung-Sutherland M, Stone I, Morris-Tilden C, Miyamoto J, McCormick R, Alley SC, Okeley N, Hayes B, Hernandez-Ilizaliturri FJ, et al: Potent antitumor activity of the anti-CD19 auristatin antibody drug conjugate hBU12-vcMMAE against rituximab-sensitive and -resistant lymphomas. Blood 113: 4352-4361, 2009.

32. Schaffar L, Dallanegra A, Breittmayer JP, Carrel S and Fehlmann M: Monoclonal antibody internalization and degradation during modulation of the $\mathrm{CD} 3 / \mathrm{T}$-cell receptor complex. Cell Immunol 116: 52-59, 1988.

33. Boyer C, Auphan N, Gabert J, Blanc D, Malissen B and Schmitt-Verhulst AM: Comparison of phosphorylation and internalization of the antigen receptor/CD3 complex, $\mathrm{CD} 8$, and class I MHC-encoded proteins on T cells. Role of intracytoplasmic domains analyzed with hybrid CD8/class I molecules. J Immunol 143: 1905-1914, 1989.
34. He J, Wang Y, Feng J, Zhu X, Lan X, Iyer AK, Zhang N, Seo Y, VanBrocklin HF and Liu B: Targeting prostate cancer cells in vivo using a rapidly internalizing novel human single-chain antibody fragment. J Nucl Med 51: 427-432, 2010.

35. Willuda J, Kubetzko S, Waibel R, Schubiger PA, ZangemeisterWittke U and Plückthun A: Tumor targeting of mono-, di-, and tetravalent anti-p185 $5^{\mathrm{HER}-2}$ miniantibodies multimerized by selfassociating peptides. J Biol Chem 276: 14385-14392, 2001.

36. Deyev SM, Waibel R, Lebedenko EN, Schubiger AP and Plückthun A: Design of multivalent complexes using the barnase-barstar module. Nat Biotechnol 21: 1486-1492, 2003.

37. Pleckaityte M, Mistiniene E, Lasickiene R, Zvirblis G and Zvirbliene A: Generation of recombinant single-chain antibodies neutralizing the cytolytic activity of vaginolysin, the main virulence factor of Gardnerella vaginalis. BMC Biotechnol 11: 100, 2011.

38. Willuda J, Honegger A, Waibel R, Schubiger PA, Stahel R, Zangemeister-Wittke $U$ and Plückthun A: High thermal stability is essential for tumor targeting of antibody fragments: Engineering of a humanized anti-epithelial glycoprotein-2 (epithelial cell adhesion molecule) single-chain Fv fragment. Cancer Res 59: 5758-5767, 1999.

39. Porter DL, Levine BL, Kalos M, Bagg A and June CH: Chimeric antigen receptor-modified $\mathrm{T}$ cells in chronic lymphoid leukemia. N Engl J Med 365: 725-733, 2011.

40. Bargou R, Leo E, Zugmaier G, Klinger M, Goebeler M, Knop S, Noppeney R, Viardot A, Hess G, Schuler M, et al: Tumor regression in cancer patients by very low doses of a $\mathrm{T}$ cell-engaging antibody. Science 321: 974-977, 2008.

41. Richters A, Sherwin RP and Richters V: The lymphocyte and human lung cancers. Cancer Res 31: 214-222, 1971.

42. Cohen $\mathrm{AB}$ and Cline MJ: The human alveolar macrophage: Isolation, cultivation in vitro, and studies of morphologic and functional characteristics. J Clin Invest 50: 1390-1398, 1971. 